\title{
Chronic demyelinating polyneuropathy associated with eosinophilia-myalgia syndrome
}

\author{
Miriam L Freimer, Jonathan D Glass, Vinay Chaudhry, William R Tyor, \\ David R Cornblath, John W Griffin, Ralph W Kuncl
}

\begin{abstract}
Eosinophilia-myalgia syndrome (EMS) is a newly described syndrome associated with use of L-tryptophan. A neuropathy with features of axonal degeneration has also been described in conjunction with EMS. Demyelinating polyneuropathy is not a well recognised association of the syndrome. The two patients with EMS reported presented with profound weakness and sensory loss and were found to have clinical, electrophysiological and pathological evidence of a chronic demyelinating polyneuropathy. The concurrence of this neuropathy with EMS, as well as several other features of their illness, is suggestive of an immune mediated mechanism in the pathophysiology of EMS.
\end{abstract}

In the autumn of 1989 the eosinophiliamyalgia syndrome (EMS) was recognised to be associated with the use of L-tryptophan. The key features of this syndrome are a raised peripheral blood eosinophil count (usually $>1000$ cells $/ \mathrm{mm}^{3}$ ); severe generalised myalgia; and absence of any infection or neoplasm that could account for the first two. ${ }^{1}$ Numerous other features may accompany these signs and symptoms, including sclerodermatous skin changes, dyspnea, cough, and inflammatory infiltrates in skin, muscle, and other tissue.

More than 1200 cases of EMS associated with L-tryptophan have been reported. ${ }^{2}$ The most frequently reported neurological manifestations of EMS are weakness and pain. These symptoms have usually been attributed to myopathy and fasciitis. Several brief statements have suggested that neuropathy may be seen in EMS. ${ }^{134}$ There are two detailed reports of associated peripheral neuropathy: one suggests a disorder predominantly due to axonal degeneration, ${ }^{5}$ and the other presents electrophysiological data consistent with demyelination but pathological data showing severe axonal degeneration. ${ }^{6}$ We reported two patients with L-tryptophan associated EMS and chronic demyelinating motor and sensory polyneuropathy. The syndrome may easily be mistaken for myopathy associated with EMS. Several clinical and pathological features of EMS associated demyelinating neuropathy suggest an immunopathogenesis.

\section{Case Reports}

\section{Case 1}

In May 1988 a 45 year old woman was given
L-tryptophan, $3 \mathrm{~g}$ nightly, for insomnia and persistent lower back pain. Sixteen months later she developed a macular rash on her forearms, thickening of the skin, and persistent low grade fever associated with increasing fatigue and weakness. In addition, she developed severe lancinating pains in her hands and feet. The peripheral blood eosinophil count was $>4000$ cells $/ \mathrm{mm}^{3}$. A full thickness skin biopsy showed fasciitis with lymphocytic infiltrates. A diagnosis of tryptophan induced EMS was made, L-tryptophan was discontinued, and prednisone $25 \mathrm{mg}$ daily was started. The rash and fevers abated and the peripheral eosinophilia disappeared; however, the pain persisted, and the weakness progressed such that by December 1989, she was bed bound. Her history revealed hypothyroidism and a remote episode of "fever of unknown origin". The family history was negative for any neuromuscular disease. She was admitted to the Johns Hopkins Hospital in February 1990. On admission she was an ill appearing woman with thickened, leathery skin. Her hands and face were swollen, and her feet and legs were oedematous and discolored. There were flexion contractures at the elbows and knees, and the "groove" sign (branching pattern of collapsed veins, reflecting the absence of dermal fibrosis at venous sites, next to otherwise sclerodermatous skin $^{7}$ ) was present on her arms. Her lungs were clear to auscultation but breath sounds were diminished. She had mild facial diplegia and ptosis but full extraocular movement. Proximal and distal limb muscles were weak: MRC grade 3 in the arms and proximal muscles of the legs and MRC grade 2 in distal leg muscles. She was unable to walk or sit up independently. Deep tendon reflexes were absent. Plantar responses were flexor. All sensory modalities were diminished in a stocking-glove pattern.

Arterial blood gas analysis showed hypoxia and a partially compensated respiratory acidosis $\left(\mathrm{PaO}_{2} 71 \mathrm{~mm} \mathrm{Hg}, \mathrm{PaCO}_{2} 74 \mathrm{~mm} \mathrm{Hg}\right.$, and pH 7.31). Vital capacity was 1.0 litre. A search for autoantibodies showed that the antiacetylcholine receptor antibody titre was $1.66 \times 10^{-9} \mathrm{M}$ (normal $<0.13 \times 10^{-9} \mathrm{M}$ ), and the IgG anti-GM1 ganglioside titre was 2216 by ELISA (normal <60; levels $>60$ commonly associated with autoimmune disorders ${ }^{89}$ ). Normal laboratory results included the following : complete blood count, routine serum chemistries, complement, antinuclear antibodies, rheumatoid factor, creatine kinase, vitamin $B_{12}$, folate, hepatitis $B$ and HIV serologies, and cerebrospinal fluid analysis. 
The absolute eosinophil count was 53 cells/ $\mathrm{mm}^{3}$. A diagnosis of EMS and demyelinating motor and sensory polyneuropathy was made based on data presented below.

The patient was given prednisone $80 \mathrm{mg}$ daily. Over the following month her skin became softer, less indurated and discolored, and less wooden, but her strength continued to deteriorate, particularly in the hands, and her sensory loss progressed to include the forearms. After she had received high dose steroids for two months her vital capacity was 0.5 litres. Nerve conduction studies showed further reduction in both distal and proximal compound muscle action potential amplitudes. She was readmitted to the hospital and given intravenous gammaglobulin $0.4 \mathrm{~g} / \mathrm{kg} /$ day for five days while being maintained on high dose steroids. After this treatment was completed her vital capacity improved to $1 \cdot 1$ litres, and her strength improved to the point that she was able to sit up independently and walk short distances with help. Over the ensuing year the patient was maintained on prednisone, 30-50 mg/day, with little functional improvement but no apparent progression of her disease.

\section{Case 2}

A 68 year old woman with a history of vitiligo and hypothyroidism had been taking L-tryptophan for insomnia, $1 \mathrm{~g}$ nightly, for more than two years. In August 1989 she stopped the medication when she was notified by the manufacturer of potential dangerous side effects. One month later she developed parotid swelling and a dry mouth. An antinuclear antibody titre was $1: 160$, and a lip biopsy showed sialoadenitis. In October 1989 she noticed dysphagia, limb weakness, and foot pain. She became unable to eat solid foods. In December she was admitted to a local hospital, severely dehydrated and profoundly hypothyroid. She was rehydrated, placed on thyroid replacement, and discharged. She was readmitted in January 1990 because of severe dehydration and a recent $18 \mathrm{~kg}$ weight loss. She was able to swallow only clear liquids. Normal laboratory results were obtained for rheumatoid factor, antibodies to double stranded DNA, erythrocyte sedimentation rate, and concentrations of creatine kinase, vitamin $B_{12}$, and aldolase. Pulmonary function tests showed a restrictive pattern.

In February 1990 she was admitted to the Johns Hopkins Hospital. Examination showed a cachectic, ill appearing woman with patches of hypopigmented skin. Her legs were mildly oedematous and the skin had a leathery quality. Neurological examination showed a distal to proximal gradient of weakness, MRC grade 4 distally and 4+ proximally. Deep tendon reflexes were reduced in the right arm and both legs and absent in the left arm. Plantar responses were flexor. There was a mild sensory loss in a stocking-and-glove distribution.

The following laboratory values were abnormal: antinuclear antibodies, 1:640; absolute eosinophil count, 480 cells $/ \mathrm{mm}^{3}$; T4 cells,
$2 \cdot 6 \mu \mathrm{g} / \mathrm{dl}$ (normal, 5.0-13.0 $\mu \mathrm{g} / \mathrm{dl}$ ); and thyroid stimulating hormone, $32.9 \mathrm{mIu} / \mathrm{ml}$ (normal, $0.5-4.5 \mathrm{mIu} / \mathrm{ml})$. IgM anti-GM1 ganglioside titre was 241 (normal, <50; levels 50-350 commonly associated with autoimmune disorders), and IgG anti-GM1 ganglioside titre was 1612 (normal < 60; levels > 60 commonly associated with autoimmune disorders ${ }^{89}$ ). Normal results were obtained for analysis cerebrospinal fluid, electrolytes, transaminases, erythrocyte sedimentation rate, creatine kinase, hepatitis B and HIV serology, and antibodies to Ro and thyroglobulin.

A lip biopsy showed severe sclerosing inflammation of the minor salivary glands. There was squamous cell metaplasia of the remaining ducts, and most of the acini were destroyed. In the context of dry mouth, this pathology substantiated a diagnosis of Sjögren's disease. ${ }^{10}$ On the basis of electrophysiological and pathological data (presented below), a diagnosis of EMS and chronic demyelinating motor and sensory polyneuropathy was made.

The patient was given prednisone $50 \mathrm{mg}$ daily, which resulted in mild improvement in her skin and her ability to walk. She continued to have difficulty swallowing and felt that her manual dexterity had worsened due to pain and stiffness. A four week course of plasma exchange (40-50 cc/kg twice weekly) was given but there was no measurable improvement. The course was complicated by multiple compression fractures and continued pain. After one year of high dose prednisone, the dose was tapered and azathioprine $(2.5 \mathrm{mg} / \mathrm{kg})$ was instituted. After four months her deep tendon reflexes returned, dramatic improvement was noted on quantitative testing of all muscles (particularly in pinch and grip, with grip strength increasing from five to 30 pounds), and all sensory modalities improved.

\section{Methods}

Motor and sensory nerve conduction studies, including late responses and electromyography were performed using standard techniques in our laboratory.

Sural nerve and an adjacent piece of gastrocnemius were biopsied from the midcalf under local anesthesia. Muscle cryosections were prepared routinely. A portion of the nerve was fixed in $5 \%$ glutaraldehyde in $0.1 \mathrm{M}$ phosphate buffer ( $\mathrm{pH} 7 \cdot 2$ ), post-fixed in osmium tetroxide and embedded in Epon. Sections $1 \mu \mathrm{m}$ thick were stained with toluidine blue for light microscopy. Thin sections were stained with uranyl acetate and lead citrate for electron microscopy.

Another portion of the nerve was snap frozen in isopentane and cryosectioned for immunocytochemistry. Staining of sections was accomplished by using the avidin-biotinperoxidase method, as previously described. ${ }^{112} \mathrm{~A}$ third portion of nerve was immersion fixed in $4 \%$ paraformaldehyde in $0.1 \mathrm{M}$ phosphate buffer ( $\mathrm{pH} 7 \cdot 2$ ) for nerve fibre teasing. Using the avidin-biotin-peroxidase complex, nerve bundles were immunostained 
Table 1 Motor nerve conduction sudies

\begin{tabular}{|c|c|c|c|c|c|}
\hline & $\begin{array}{l}\text { Distal latency } \\
\text { (ms) }\end{array}$ & $\begin{array}{l}\text { Conduction velocity } \\
(\mathrm{m} / \mathrm{s})\end{array}$ & $\begin{array}{l}\text { Baseline to negative peak } \\
\text { distal amplitude }(\mu V)\end{array}$ & $\begin{array}{l}\text { Baseline to negative peak } \\
\text { proximal amplitude }(\mu V)\end{array}$ & $\begin{array}{l}\text { Minimum } F \text { wave } \\
\text { latency (ms) }\end{array}$ \\
\hline $\begin{array}{l}\text { Peroneal nerve: } \\
\text { Case } 1 \\
\text { Case } 2 \\
\text { Normal }\end{array}$ & $\begin{array}{r}5 \cdot 5 \\
4.6 \\
\leqslant 5.5\end{array}$ & $\begin{array}{r}34 \\
33 \\
\geqslant 40\end{array}$ & $\begin{array}{r}1200 \\
3500 \\
\geqslant 2000\end{array}$ & $\begin{array}{r}900 \\
1000 \\
\geqslant 2000\end{array}$ & $\begin{array}{r}50 \cdot 5 \\
63 \cdot 4 \\
\leqslant 55 \cdot 0\end{array}$ \\
\hline $\begin{array}{l}\text { Ulnar nerve: } \\
\text { Case } 1 \\
\text { Case } 2 \\
\text { Normal }\end{array}$ & $\begin{array}{r}6.5 \\
2.8 \\
\leqslant 3.4\end{array}$ & $\begin{array}{r}18 \\
34 \\
\geqslant 50\end{array}$ & $\begin{array}{r}1200 \\
8500 \\
\geqslant 4000\end{array}$ & $\begin{array}{r}250 \\
4110 \\
\geqslant 4000\end{array}$ & $\begin{array}{r}53 \cdot 7 \\
36 \cdot 6 \\
\leqslant 32 \cdot 0\end{array}$ \\
\hline $\begin{array}{l}\text { Median nerve: } \\
\text { Case } 1 \\
\text { Case } 2 \\
\text { Normal }\end{array}$ & $\begin{array}{r}4 \cdot 5 \\
4 \cdot 7 \\
\leqslant 4 \cdot 2\end{array}$ & $\begin{array}{r}38 \\
32 \\
\geqslant 50\end{array}$ & $\begin{array}{r}5000 \\
3500 \\
\geqslant 4000\end{array}$ & $\begin{array}{r}5000 \\
1100 \\
\geqslant 4000\end{array}$ & $\begin{array}{r}29.0 \\
38.6 \\
\leqslant 31.0\end{array}$ \\
\hline
\end{tabular}

for macrophages with $E B M / 11,{ }^{13}$ infiltrated with glycerol, and teased with fine needles.

\section{Results}

ELECTROPHYSIOLOGICAL STUDIES

Case 1

Electrophysiological studies showed a demyelinating motor and sensory polyneuropathy (tables 1 and 2). Distal latencies were prolonged in five of six motor nerves, as were $F$ wave latencies in two of six nerves. In the left ulnar nerve the forearm conduction velocity was severely reduced $(18 \mathrm{~m} / \mathrm{s})$. The results of surface recording and stimulation suggested partial motor conduction block in the right ulnar and tibial nerves. ${ }^{14}$ In addition, abnormal temporal dispersion was present in the right ulnar and peroneal nerves. Compound muscle action potential amplitudes were reduced in five of six motor nerves.

Electromyography showed myopathic voluntary motor unit potentials without abnormal spontaneous activity in the proximal and distal muscles.

A follow up study was performed five weeks later. In all motor nerves the distal evoked amplitudes were reduced further than in the previous study. Distal latencies were further prolonged in the tibial and ulnar nerves, and conduction velocities were further reduced in all motor nerves. The $F$ wave latency was prolonged in the tibial nerve and absent in the peroneal nerve. The results of surface recordings and stimulation in the left ulnar nerve suggested partial motor conduction block.

Case 2

The nerve conduction studies were interpreted as a demyelinating motor and sensory poly-

Table 2 Sensory nerve conduction studies

\begin{tabular}{llc}
\hline & $\begin{array}{l}\text { Conduction } \\
\text { velocity }(\mathrm{m} / \mathrm{s})\end{array}$ & $\begin{array}{l}\text { Peak to peak } \\
\text { amplitude }(\mu \mathrm{V})\end{array}$ \\
\hline Sural nerve: & NR & \\
$\quad$ Case 1 & 46 & 8 \\
Case 2 & $\geqslant 40$ & $\geqslant 10$ \\
$\quad$ Normal & 38 & 6 \\
Median nerve: & & 9 \\
Case 1 & 48 & 910 \\
Case 2 & $\geqslant 50$ & \\
Normal & & 4 \\
Ulnar nerve: & NR & \\
Case 1 & 48 & $\geqslant 10$ \\
Case 2 & $\geqslant 50$ & \\
Normal & & \\
\hline
\end{tabular}

NR $=$ no response. neuropathy, (tables 1 and 2). Conduction velocities were reduced and $F$ wave latencies were prolonged in all motor nerves. Distal motor latencies were prolonged in two of three nerves. Partial motor conduction block was suggested by the results of surface recording and stimulation in the right median and ulnar nerves. ${ }^{14}$ Abnormal temporal dispersion was present in the right peroneal nerve.

Needle electromyography revealed short duration, low amplitude, polyphasic motor units in proximal muscles. Abnormal spontaneous activity was observed only in distal muscles, where voluntary motor unit potentials were normal. The electromyography findings were consistent with a proximal myopathy and a distal neuropathy.

A follow up study was performed four months later. Further reduction in all motor conduction velocities was seen. $F$ wave latencies were further prolonged or absent. Motor evoked amplitudes were further reduced, with one nerve being $5 \%$ of the lower limit of normal.

\section{NEUROPATHOLOGY}

Case 1

A biopsy of sural nerve showed enlargement of the nerve with extensive epineurial thickening as a result of collagen deposition (fig 1). Both epineurium and endoneurium had scattered inflammation, and there was rimming of the perineurium with mononuclear cells. The density of large and small myelinated fibres was noticeably reduced. Many thinly myelinated fibres were seen, suggesting remyelination. One fascicle (fig 1B) was extensively demyelinated, illustrating the inhomogeneous pattern of these changes. The epineurial and endoneurial blood vessel walls were thickened. Electron microscopy (fig 1C, D) showed evidence of prior and active demyelination; some fibres had intratubal macrophages splitting myelin lamellae.

Examination of teased fibres confirmed extensive demyelination and remyelination; in one fascicle, $38 \%$ of fibres had demyelinated or demyelinating internodes; in a second fascicle, $8 \%$ of fibres were affected. By immunostaining for macrophage markers, the demyelinating fibres had adherent and intratubal macrophages (fig lE). Remyelinated fibres and fibres undergoing active Wallerian-like degeneration were also identified. Immunostaining of frozen 
Figure 1 Sural nerve from patient 1. (A) Light photomicrograph shows extensive thickening of both epineurium and

perineurium (bar =

$200 \mu \mathrm{m})$. (B) One fascicle (box in $A$ ) shows features of active demyelinating neuropathy, including naked axons (arrowheads) and large thinly myelinated fibres that imply

remyelination (arrows)

$($ bar $=40 \mu \mathrm{m})$. (C)

Electron micrograph

showing completely

demyelinated axon

(asterisk) (bar $=5 \mu \mathrm{m}$ ).

(D) Macrophage (M) is actively stripping myelin from axon. Note tongue of macrophage cytoplasm interdigitating between myelin lamellae (arrow) (bar $=5 \mu \mathrm{m}$ ). (E) Teased fibre immunostained with $E B M / 11$, an antibody to macrophages, showing adherence of macrophages to nerve fibre (arrows) (bar $=20 \mu \mathrm{m})$.

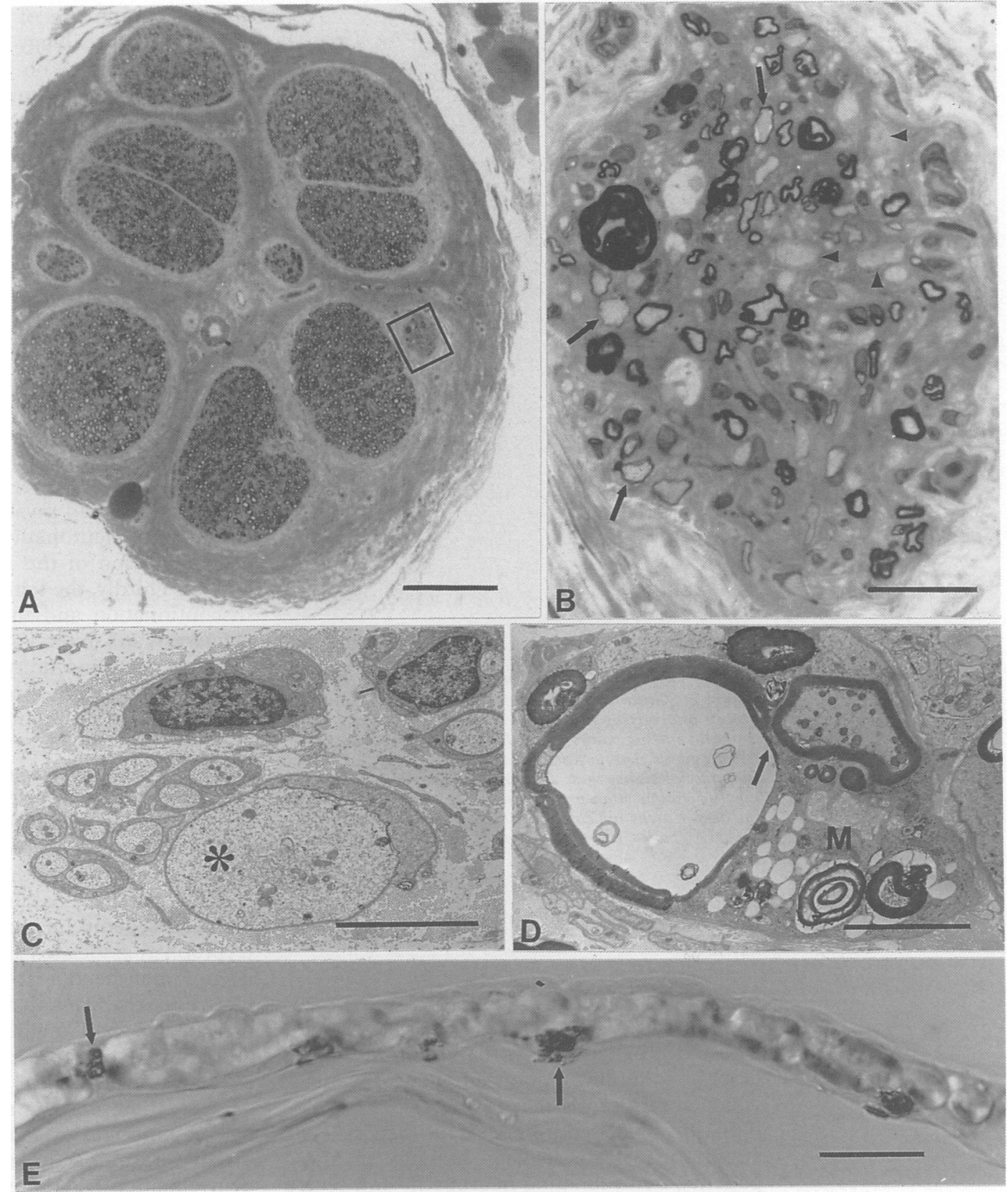

sections with a $\mathrm{T}$ cell marker showed scattered $T$ cells throughout the perineurium.

A biopsy of gastrocnemius muscle (fig 2) showed widespread fibrosis of the overlying fascia and endomysial connective tissue. Close to the fascial plane the muscle fibres were atrophic and basophilic, often distorted and embedded in collagen. Split fibres and fibres with abnormal internal architectural changes also occurred. In a gradient farther from the fascial plane these changes became milder. Throughout the biopsy, focal grouped atrophy, fibre type grouping, and pyknotic nuclear clumps were seen. The intramuscular capillary walls were thickened and fibrotic. No inflammatory infiltrates were seen. These findings were interpreted as consistent with denervation and coexisting fasciopathy, which was a likely residue of severe fasciitis.

Case 2

A biopsy of the sural nerve showed thickening of both the epineurium and perineurium, with particularly dramatic rimming with mononuclear cells, indicating active perineuritis (figs 3A, B). Ongoing demyelination as well as Wallerian-like degeneration were apparent. The density of large and small myelinated fibres was slightly reduced. Electron microscopy showed scattered demyelinated fibres and some remyelinating fibres, along with frequent endoneurial inflammatory cells (fig 3C). Immunostaining of frozen sections with Leu4 and Dako antibodies showed prominent rimming of the perineurium with $T$ cell lymphocytes (figs 3D, E) and macrophages.

The gastrocnemius muscle biopsy showed diffuse thickening of the fascial plane and endomysial connective tissue. There were changes consistent with a neuropathic process, including fibre type grouping and small angular fibres. In addition, a gradient of myopathic changes, including rounded atrophic fibres, central nuclei, and split fibres, extended from 


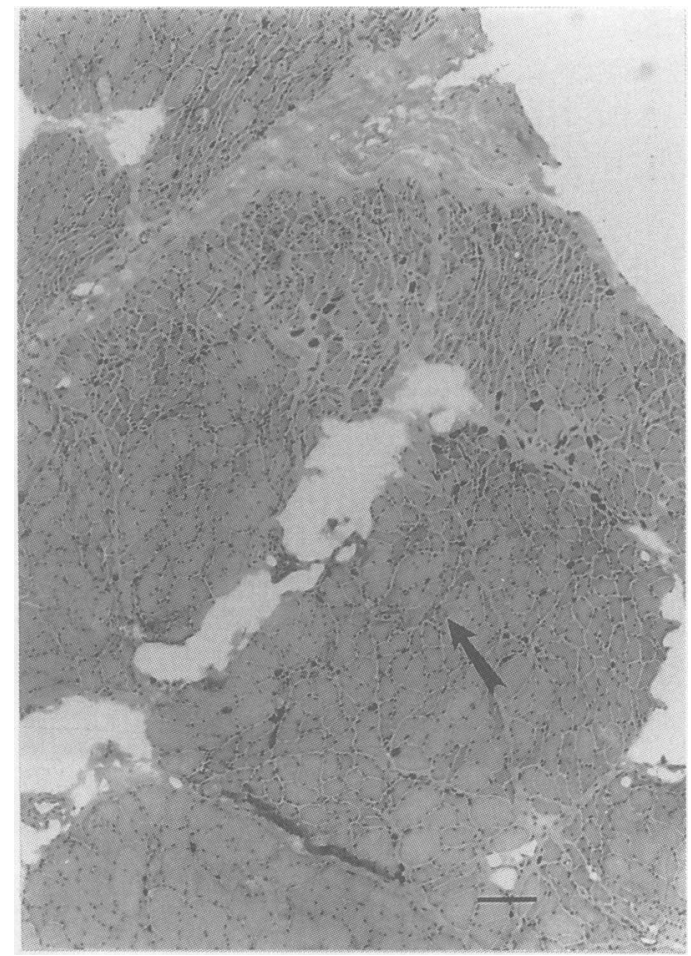

Figure 2 Gastrocnemius muscle from patient 1. Marked fibrosis of overlying fascia and all layers of investing connective tissue occurs in gradient from surface inward. Muscle fibres close to fascial plane are distorted; farther from fascial plane, these changes are less severe. Pyknotic nuclear clumps (thin arrow) and grouped atrophy seen in the deeper areas indicate coexistant denervation atrophy

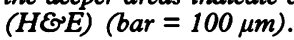

the muscle fibres adjacent to the fascia inward.

\section{Discussion}

These two patients show the symptoms, signs, laboratory findings, and pathological changes which comprise the recently described eosinophilia-myalgia syndrome. ${ }^{1}$ This report calls attention to two striking findings in these patients: demyelinating neuropathy and severe perineuritis. Unlike the vast majority of patients with EMS, these two patients developed rapidly progressive weakness. The weakness occurred with a distal to proximal gradient, accompanied by mild wasting and moderate sensory loss. Reflexes were reduced or absent. Nerve conduction studies showed a severe demyelinating motor and sensory polyneuropathy. The nerve biopsies confirmed ongoing demyelination and remyelination and active inflammation. This constellation of findings suggests an acquired demyelinating polyneuropathy. Such neuropathies are postulated to be immunopathogenic. ${ }^{15}$

The eosinophilia-myalgia syndrome appeared as an epidemic in $1989 .^{1216-18}$ The syndrome is characterised physically by the acute onset of pain, oedema, and induration of the legs, arms, and trunk. Other prominent features may include weakness, cough, and dyspnea. Pathological findings in the skin include perivascular collections of lymphocytes, eosinophils, and plasma cells and excessive collagen deposition. EMS has been linked to the chronic use of L-tryptophan, but the exact pathophysiology is unknown. Speculation has centred on three hypotheses: (a) L-tryptophan may trigger an autoimmune response in some susceptible individuals; ${ }^{16}$ (b) EMS is due to a contaminant of some preparations of the drug; or (c) EMS may be due to faulty tryptophan metabolism.

The autoimmune hypothesis may be supported by several notable features of these cases. Firstly, both patients, before being exposed to L-tryptophan, had a strong history of other disorders thought to be autoimmune. Secondly, after exposure to L-tryptophan both patients also had high concentrations of several autoantibodies in their serum samples. The presence of anti-acetylcholine receptor antibodies in patient 1 and anti-GM1 antibodies in both patients does not necessarily imply that these patients had myasthenia gravis or multifocal motor neuropathy ${ }^{8}$; rather, it suggests that regulation of the immune system is disturbed. Thirdly, the temporal lag between drug discontinuation and the onset of the disease suggests an intervening mechanism (for example, autoimmunity) rather than a direct toxic mechanism. A fourth clinical feature that supports the autoimmune hypothesis is the apparent improvement of patient 1 after one course of intravenous gammaglobulin ${ }^{19-22}$ and the dramatic improvement of patient 2 after four months of azathioprine treatment. Finally, inflammation was a prominent part of the neuropathology in both cases.

What is the pathophysiological relation between a demyelinating polyneuropathy and tryptophan associated EMS? While their coexistence may be due to chance, several speculative mechanisms may be considered. EMS or L-tryptophan might trigger a widespread autoimmune response, as suggested above. Or, as the morphological data presented here suggest, there may be more specific targeting by the immune system of peripheral nerve myelin, resulting in macrophage mediated demyelination. Perhaps L-tryptophan or a contaminant serves as an antigen or antigenic modifier (adjuvant), stimulating the immune system to recognise self antigens in peripheral nerve myelin. Those patients with EMS who developed demyelinating polyneuropathy may have a latent hypersensitivity to nerve antigen that is activated by the L-tryptophan preparation. Both our patients had a strong history of immune dysfunction which may have predisposed them to develop either demyelinating neuropathy or EMS. A similar mechanism was proposed in a patient with procainamide induced polyradiculopathy who showed lymphocyte sensitisation to peripheral nerve myelin and procainamide. ${ }^{23}$

The similarities between the neuropathy descibed in this paper and chronic inflammatory demyelinating polyradiculopathy (CIDP) should be noted because CIDP is generally considered to be a disorder of the immune system. $^{2324}$ Electrophysiologically, our patients' neuropathy was indistinguishable from CIDP. ${ }^{15}$ Clinically, both present with predominantly motor dysfunction and hypore- 
Figure 3 Sural nerve from patient 2. (A) Light photomicrograph showing thickening of epineurium and perineurium and active perineurial inflammation (toluidine blue) (bar $=100 \mu \mathrm{m})$.

(B) Blood vessel typical of those seen throughout the biopsy shows perivascular mononuclear cells (toluidine blue) (bar = $35 \mu \mathrm{m})$. (C)

Completely demyelinated axon $(E M, b a r=1 \mu \mathrm{m})$. (D) Frozen section of nerve immunostained with Leu4, an antibody to CD3 antigens on $T$ cells, showing extensive rimming of all fascicles with $T$ cells

(bar $=200 \mu \mathrm{m})$. (E)

Boxed area (from D) is

shown at higher power and shows intensity of

inflammatory infiltrate (bar $=60 \mu \mathrm{m}$ ).
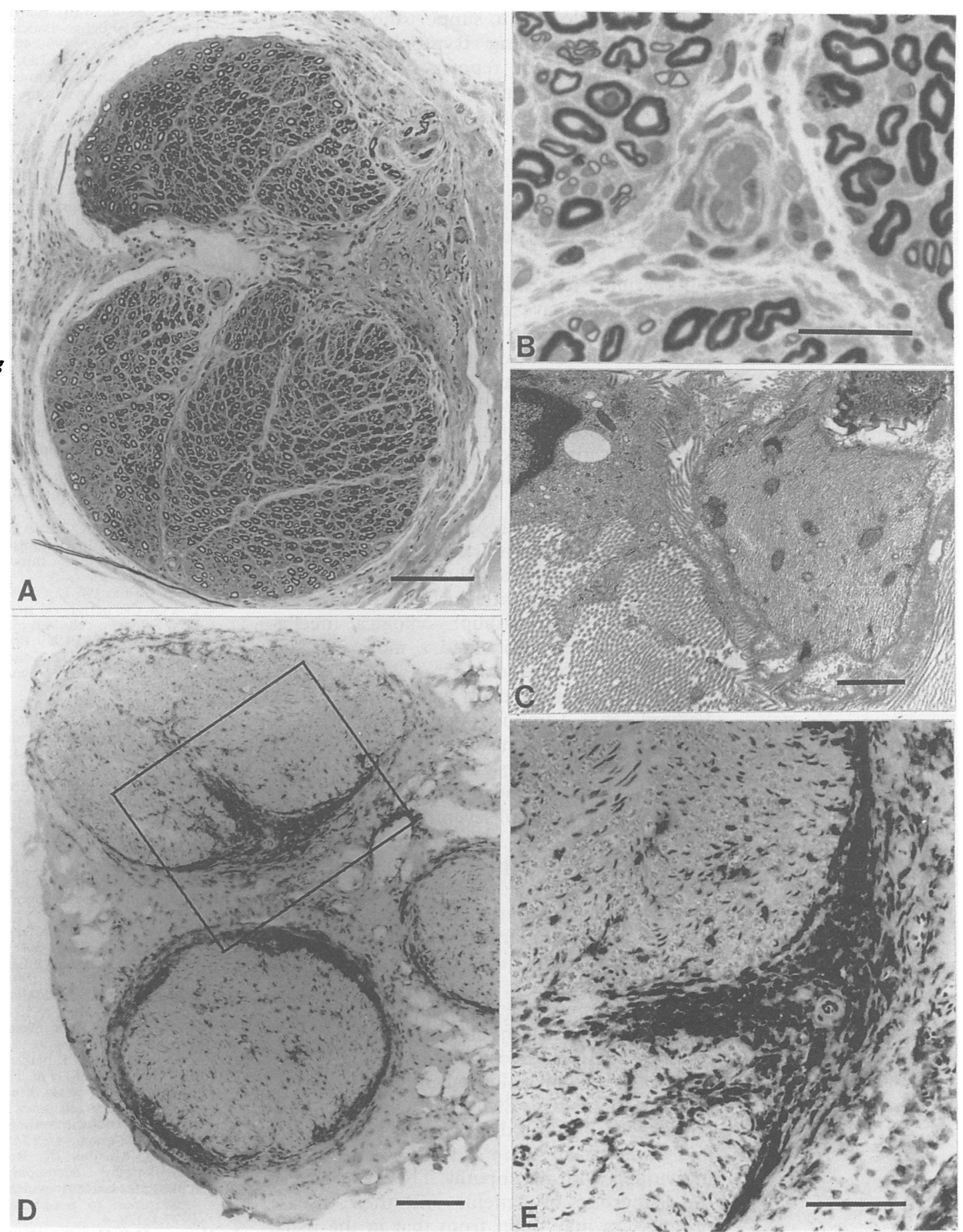

flexia. Our patients differed from those with CIDP pathologically because there was pronounced fibrosis and perineuritis in our patients. In addition, the abnormalities of muscle are not found in patients with CIDP.

One final analogy that suggests an autoimmune mechanism is the remarkable resemblance of EMS to eosinophilic fasciitis (EF), first described by Shulman in 1975. Patients with EF develop cutaneous lesions similar to those described in EMS, as well as fascial inflammation, weakness, and peripheral eosinophilia. ${ }^{25}{ }^{26}$ The oetiology of EF is unclear, but EF has occurred in association with hypergammaglobulinaemia and in association with autoimmune syndromes such as vitiligo, thyroid disease, and Sjögren's syndrome. To date, there is no strong evidence to link EF with L-tryptophan. ${ }^{2}$

In favour of a toxic substance causing EMS is the presence of an unidentified chemical found in some retail lots of L-tryptophan which were consumed by patients who developed EMS. ${ }^{27}$ Perhaps this "toxin" triggers the eosinophilic proliferation in EMS. The subsequent nerve damage could then be due to eosinophil derived neurotoxins. ${ }^{52-30}$ This might explain why the polyneuropathy most commonly seen in EMS is predominantly due to axonal degeneration; however, this would not account for the inflammation, demyelination, and other features seen in our patients. 
There is little data to support the remaining hypothesis concerning tryptophan and its metabolism. Recent reports have suggested that levels of kynurenine, a major product of L-tryptophan metabolism, are increased in patients with EMS compared with control patients. ${ }^{16}$ In addition, two patients with EMS and neuropathy had raised concentrations of the excitotoxin quinolinic acid, a final product of L-tryptophan metabolism, in cerebrospinal fluid.

Experience in treating EMS is limited. While some patients have responded to corticosteroids, those patients with the more severe forms of the disease, including the neuropathies and pulmonary disease, may not. One of our patients improved clinically after receiving gammaglobulin, but she continues to have debilitating pain and weakness. The other patient remained stable on long term, high dose prednisone and has shown considerable improvement on azathioprine. Other immune treatments have been tried, including cyclosporin, plasmapheresis, hydroxychloroquine, and methotrexate, with variable success. ${ }^{31}{ }^{32}$ Perhaps when the pathophysiological mechanism of EMS is delineated a more effective treatment will be developed.

Although L-tryptophan was banned by the Federal Drug Administration in March 1990, patients with this syndrome may continue to present to neurologists and rheumatologists for several reasons. Firstly, symptoms may not become apparent until several months after the discontinuation of the drug. Secondly, although both our patients had long since discontinued the medication, they continued to show disease progression. Lastly, although L-tryptophan is no longer available in stores, it may remain in medicine cabinets for many years.

In conclusion, we draw attention to the important association of demyelinating neuropathy with the eosinophilia-myalgia syndrome. Electrophysiological studies are important in patients with EMS, particularly in those patients with a rapidly progressive proximal and distal weakness, in order to identify those individuals with neuropathy. The treatment of this subgroup of patients and their disease progression may differ from that in the usual EMS patient.

This work was supported by The Muscular Dystrophy Association (MLF), The Jay Slotkin Fund for Neuromuscular Research tion (MLF), The Jay Slotkin Fund for Neuromuscular Research NS26643 (WRT) and NS 07179 (JDG). We thank Dr Ronenn NS26643 (WRT) and NS 07179 (JDG). We thank Dr Ronenn Roubenoff and Dr William Ravich for referring their patients; Yan Li for preparation of teased fibres. Rod Graham prepared Yan $\mathrm{Li}$ for preparation of teased fibres. Rod Grah
the manuscript and offered editorial assistance.

1 Eosinophilia-myalgia syndrome and L-tryptophan-containing products-New Mexico, Minnesota, Oregon, and New York. MMWR 1989;38:785-8.

2 Medsger TA. Tryptophan-induced eosinophilia-myalgia syndrome. $N$ Engl f Med 1990;322:926-8.
3 Selwa JF, Feldman EL, Blaivas M. Mononeuropathy multiplex in tryptophan-associated eosinophilia-myalgia syn40:1632-3.

4 Seidman RI, Kaufman LD, Sokoloff L, Miller F, Iliya A, Peress NS. The neuromuscular pathology of the eosinophilia-myalgia syndrome. $\mathcal{f}$ Neuropathol Exp Neurol 1991;5:49-62.

5 Smith BE, Dyck PJ. Peripheral neuropathy in the eosinophilia-myalgia syndrome associated wtih L-tryptophan ingestion. Neurology 1990;40:1035-40.

6 Heiman-Patterson TD, Bird SJ, Parry GJ, Varga J, Shy ME, Culligan NW, et al. Peripheral neuropathy associated with eosinophilia-myalgia syndrome. Ann Neurol 1990;28: 522-8.

7 Case records of the Massachusetts General Hospital (Case 4-199). N Engl f Med 1990;322:252-61.

8 Pestronk A, Cornblath DR, Ilyas AA, Baba H, Quarles RH, Griffin JW, et al. A treatable multifocal motor neuropathy with antibodies to GM1 ganglioside. Ann Neurol 1988; 24:73-8.

9 Pestronk A, Adams RN, Clawson L Cornblath D, Kuncl RW, Griffin D, et al. Serum antibodies to GM1 ganglioside in amyotrophic lateral sclerosis. Neurology 1988; 38:1457-61.

10 Greenspan JS, Daniels TE, Talal N, Sylvester RA. The histopathology of Sjögren's syndrome in labial salivary gland biopsies. Oral Pathol 1974;37:217-29.

$11 \mathrm{Hsu}$ SM, Raine L, Fanger H. The use of avidin-biotinperoxidase complex (ABC) in the immunoperoxidase techniques-a comparison between $\mathrm{ABC}$ and unlabeled antibody (PAP) procedures. $f$ Histochem Cytochem 1981;29:577-80.

12 Tyor WR, Stoll G, Griffin DE. The characterization of Ia expression during sindbis virus encephalitis in normal and athymic nude mice. $f$ Neuropathol Exp Neurol and athymic nud

13 Stoll G, Griffin JW, Li CY, Trapp BD. Wallerian degeneration in the peripheral nervous system: participation of tion in the peripheral nervous system: participation of tion. $₹$ Neurocytol $1989 ; 18: 671-83$.

14 Brown WF, Feasby TE. Conduction block and denervation in Guillain-Barré polyneuropathy. Brain 1984;107: 219-39.

15 Cornblath DR, Asbury AK, Albers JW, Feasby TE, Hahn AF, McLeod JG, et al. Research criteria for diagnosis of chronic inflammatory demyelinating polyneuropathy (CIDP). Neurology 1991;41:617-8.

16 Silver RM, Heyes MP, Maize JC, Quearry B, VionnetFuasset M, Sternberg EM. Scleroderma, fasciitis, and eosinophilia associated with the ingestion of tryptophan. $N$ Engl $\mathcal{F}$ Med 1990;322:874-81.

17 Eosinophilia-myalgia syndrome-New Mexico. MMWR 1989;38:75-7.

18 Hertzman PA, Blevins WL, Mayer J, Greenfield B, Ting M, Gleich GJ. Association of the eosinophilia-myalgia synGleich GJ. Association of the eosinophilia-myalgia syn-
drome with the ingestion of tryptophan. $N$ Engl $f$ Med 1990;322:869-73.

19 Van Doorn PA, Brand A, Strengers PFW, Meulstee J, Vermeulen M. High-dose intravenous immunoglobulin treatment in chronic inflammatory demyelinating polyneuropathy. Neurology 1990;40:209-12.

20. Gajdos PH, Outib H, Elkharrat D, Brunel D, de RohanChabot P, Raphael JC, et al. High-dose intravenous gamma globulin for myasthenia gravis. Lancet 1984;i: 406-7.

21 Furusho K, Kamiya T, Nakano H, Kryosawa N, Shinomiya $\mathrm{K}$, Hayashidera $\mathrm{T}$, et al. High-dose intravenous gammaglobulin for Kawasaki disease. Lancet 1984;ii:1055-8.

22 Arsura EL, Bick A, Brunner NG, Namba T, Grob D. Highdose intravenous. immunoglobulin in the management of myasthenia gravis. Arch Intern Med 1986;146:1365-8.

23 Zahenk J, Mendell JR, Rossio JL, Hurtubise P. Polyradiculopathy accompanying procainamide-induced radiculopathy accompanying procainamide-induced
lupus enthematosus: evidence for drug-induced enhanced lupus enthematosus: evidence for drug-induced enhanced
sensitization to peripheral nerve myelin. Ann Neurol 1977;1:378-4.

24 Hartung H-P, Heininger K, Schafer B, Fierz W, Toyka KV. Immune mechanisms in inflammatory polyneuropathy. Ann NY Acad Sci 1988;540:122-61.

25 Doyle JA, Ginsburg WW. Eosinophilic fasciitis. Med Clin N Amer 1987;73:1157-66.

26 Shulman LE. Diffuse fasciitis with eosinophilia: a new syndrome? Trans Assoc Amer Physicians 1975;8:70-86.

27 Belongia EA, Hedberg CW, Gleich GJ, White KE, Mayeno AN, Loegering DA, et al. An investigation of the cause of the eosinophilia-myalgia syndrome associated with typtophan use. N Engl $\mathcal{F}$ Med 1990;323:357-65.

28 Moore PM, Haney JB, Fauci AS. Neurologic dysfunction in the idiopathic hypereosinophilia syndrome. Ann Intem Med 1985;102:109-14.

29 Durack DT, Sumi SM, Klebanoff SJ. Neurotoxicity of human eosinophils. Proc Natl Acad Sci USA 1979;76: 1443-7.

30 Sunohara N, Furukawa S, Nishio T, Mukoyama M, Satoyoshi E. Neurotoxicity of human eosinophils towards peripheral nerve. $¥$ Neurol Sci 1989;92:1-7.

31 Clauw DJ, Katz P. Treatment of the eosinophilia-myalgia syndrome. N Engl f Med 1990;323:417.

32 Hertman PA, Gleich G. Treatment of the eosinophiliamyalgia syndrome. $N$ Engl $\mathcal{F}$ Med 1990;323:417-8. 